\title{
Pipeline Embolization Device with or without Adjunctive Coil Embolization: Analysis of Complications from the IntrePED Registry
}

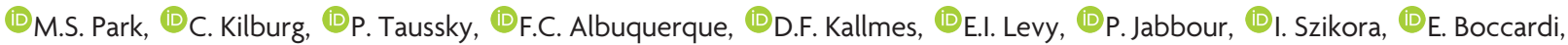 \\ (1D.A. Hanel, 1 A. Bonafé, and (1DC.G. McDougall
}

\begin{abstract}
SUMMARY: Flow diversion to treat cerebral aneurysms has revolutionized neurointerventional surgery. Because the addition of coils potentially increases the time and complexity of endovascular procedures, we sought to determine whether adjunctive coil use is associated with an increase in complications. Patients in the International Retrospective Study of Pipeline Embolization Device registry were divided into those treated with the Pipeline Embolization Device alone ( $n=689$ patients; $n=797$ aneurysms; mean aneurysm size, $10.3 \pm 7.6 \mathrm{~mm}$ ) versus those treated with the Pipeline Embolization Device and concurrent coil embolization $(n=104$ patients; $n=109$ aneurysms; mean aneurysm size, $13.6 \pm 7.8 \mathrm{~mm}$ ). Patient demographics and aneurysm characteristics were examined. Rates of neurologic morbidity and mortality were compared between groups. The Pipeline Embolization Device with versus without coiling required a significantly longer procedure time $(135.8 \pm 63.9$ versus $96.7 \pm 46.2 \mathrm{~min} ; P<.0001)$ and resulted in higher neurological morbidity $(12.5 \%$ versus $7.8 \% ; P=.13$ ). These data suggest that either strategy represents an acceptable risk profile in the treatment of complex cerebral aneurysms and warrants further investigation.
\end{abstract}

ABBREVIATIONS: IntrePED = International Retrospective Study of Pipeline Embolization Device; PED = Pipeline Embolization Device

$\mathbf{T}$ he recent development of flow diversion for cerebral aneurysms that are difficult to treat has ushered in an exciting time in the world of neurointerventional surgery. ${ }^{1-17}$ Reports in the literature, however, are conflicting concerning the optimal strategy in using this new device. , 2,4,13,15,16,18-21 $^{\text {The addition of coil }}$ embolization to flow diversion, while prevalent in daily use, has not been subjected to a large systematic analysis. ${ }^{7-11,16,21-24}$ The earliest case report hypothesized that coils within the aneurysm sac can augment the degree of flow diversion with the goal of improved occlusion of the aneurysm. ${ }^{1}$ Others believe that adjunctive coil embolization does little to improve the already high occlusion rates obtained by using the Pipeline Embolization Device (PED; Covidien, Irvine, California) alone. ${ }^{21}$ Furthermore, there

Received July 14, 2015; accepted after revision November 18.

From the Department of Neurosurgery (M.S.P., C.K., P.T.), University of Utah Health Care, Salt Lake City, Utah; Department of Neurosurgery (F.C.A., C.G.M.), Barrow Neurological Institute, Phoenix, Arizona; Department of Radiology (D.F.K.), Mayo Clinic, Rochester, Minnesota; Department of Neurosurgery (E.I.L.), University of Buffalo, Buffalo, New York; Department of Neurosurgery (P.J.), Thomas Jefferson University, Philadelphia, Pennsylvania; Department of Neurointerventions (I.S.), National Institute of Neurosciences, Budapest, Hungary; Department of Neuroradiology (E.B.), Ospedale Niguarda Ca' Granda, Milan, Italy; Department of Neurosurgery (R.A.H.), Baptist Health, Jacksonville, Florida; and Department of Neuroradiology (A.B.), Hôpital Gui de Chauliac, Montpellier, France.

Please address correspondence to Cameron G. McDougall, MD, c/o Neuroscience Publications; Barrow Neurological Institute, St. Joseph's Hospital and Medical Center, 350 W Thomas Rd, Phoenix, AZ 85013; e-mail: Neuropub@dignityhealth.org

http://dx.doi.org/10.3174/ajnr.A4678 have been reports of complications associated with overly dense coil embolization of aneurysms in this setting. ${ }^{22}$

We analyzed the International Retrospective Study of Pipeline Embolization Device (IntrePED [ClinicalTrials.gov identifier: NCT01558102]) data to determine whether there was an increase in neurologic complications associated with the use of the PED and adjunctive coil embolization.

\section{MATERIALS AND METHODS}

This study is a subanalysis of IntrePED registry data obtained from a multicenter, observational, international registry of patients treated with the PED. The primary objective of IntrePED was to identify any neurologic events following treatment with the PED. The IntrePED registry includes patients treated with the PED starting in July 2008 and concluding in July 2013, following the enrollment of 793 patients. Because the study was conducted retrospectively, the protocol did not specify the coiling methodology, and the decision to use coils with the PED was left to the discretion of the treating physician. Details regarding the institutional review board and ethics committee approvals, patient population, and protocol requirements are described in the primary IntrePED article. ${ }^{17}$

This subanalysis was performed to compare the safety outcomes of patients treated with the PED alone (PED group) with those of patients treated with the PED and adjunctive coil embolization (PED/coil group). Data collected for analysis were basic 
Table 1: Patient details

\begin{tabular}{lccc}
\hline Patient Characteristics & PED/Coils & PED Alone & $\boldsymbol{P}$ Value $^{\mathbf{a}}$ \\
\hline No. (\%) of aneurysms & $109(12.0 \%)$ & $797(88.0 \%)$ & \\
No. (\%) of patients & $104(13.1 \%)$ & $689(86.9 \%)$ & \\
Age (yr) & & & .279 \\
$\quad$ Mean & $57.6 \pm 15.1$ & $56.8 \pm 14.0$ & \\
$\quad$ Median, range & $61.5 ; 3-81$ & $57 ; 9-86$ & \\
Sex (No., \%) & & & .435 \\
$\quad$ Male & $24(23.1 \%)$ & $137(19.9 \%)$ & \\
$\quad$ Female & $80(76.9 \%)$ & $552(80.1 \%)$ & \\
Follow-up duration (mo) & & & .718 \\
$\quad$ Mean & $21.1 \pm 8.8$ & $22.1 \pm 8.8$ & \\
$\quad$ Median, range & $20.8 ; 0.1-45.0$ & $21.0 ; 0.1-60.5$ & \\
Procedure time (min) & & & $<.0001$ \\
$\quad$ Mean & $135.8 \pm 63.9$ & $96.7 \pm 46.2$ & \\
$\quad$ Median, range & $120 ; 46-365$ & $87 ; 10-376$ & \\
\hline
\end{tabular}

a $P$ values for age, duration of follow-up, and procedure time were calculated with Wilcoxon rank sum tests. $P$ value for sex was calculated with the $\chi^{2}$ test.

demographic information, including patient age, sex, and history of aneurysm rupture; aneurysm characteristics, including aneurysm size, neck size, shape, and location; procedural data, including procedure time and devices used; and follow-up data, including any complications. The primary outcomes were neurologic mortality and combined neurologic morbidity and mortality. Neurologic morbidity was predefined as the composite of the following neurologic complications: spontaneous aneurysm rupture, ipsilateral intracranial hemorrhage, ischemic stroke, parent artery stenosis, and cranial neuropathy. These complications were characterized as major or minor, with "major" defined as an ongoing clinical deficit at 7 days after the event. All major adverse events are included in the neurologic morbidity and mortality rates.

The data were analyzed to determine whether there were any significant differences between those patients treated with the PED alone versus those treated with the PED and adjunctive coils. Differences in continuous variables between the 2 groups were tested by using the Wilcoxon rank sum test. Differences in categoric variables between groups were analyzed by using the $\chi^{2}$ or Fisher exact test. Data are presented as the number of events and percentage or mean \pm SD unless otherwise noted; $P$ values $<.05$ were statistically significant. Most statistical analyses were performed across patient groups on a per-patient basis. When determining aneurysm size, we categorized patients with multiple aneurysms on the basis of the size of the largest aneurysm. Analysis of aneurysm characteristics was performed across all aneurysms rather than across patients.

\section{RESULTS}

The registry included 793 patients with 906 aneurysms: 689 patients with 797 aneurysms were treated with the PED alone, and 104 patients with 109 aneurysms were treated with PED/coil (Table 1). While the patient ages, sex, and length of follow-up were well matched, procedure times were significantly increased for the PED/coil cohort compared with the PED alone group (135.8 \pm 63.9 minutes versus $96.7 \pm 46.2$ minutes, $P<.0001)$.

The mean aneurysm and neck sizes were statistically larger in the PED/coil cohort than in the PED alone group (aneurysm size, $13.6 \pm 7.8 \mathrm{~mm}$ versus $10.3 \pm 7.6 \mathrm{~mm}, P<.0001$; neck size, $6.4 \pm$ $3.0 \mathrm{~mm}$ versus $6.2 \pm 5.1 \mathrm{~mm}, P=.017$ ) (Table 2). These larger
Table 2: Aneurysm characteristics

\begin{tabular}{lccc}
\hline \multicolumn{1}{|c}{ Aneurysm Characteristics } & PED/Coils & PED Alone & P Value $^{\mathbf{a}}$ \\
\hline No. of aneurysms & 109 & 797 & \\
No. of patients & 104 & 689 & \\
Aneurysm size (mm) & & & $<.0001$ \\
$\quad$ Mean & $13.6 \pm 7.8$ & $10.3 \pm 7.6$ & \\
$\quad$ Median, range & $12 ; 1.6-45.0$ & $8 ; 1.0-55.0$ & \\
Aneurysm neck (mm) & & & .017 \\
$\quad$ Mean & $6.4 \pm 3.0$ & $6.2 \pm 5.1$ & \\
$\quad$ Median, range & $6 ; 0.8-16.0$ & $5 ; 0.9-53.0$ & \\
Aneurysm shape (No., \%) & & & .3366 \\
$\quad$ Fusiform & $13(11.9 \%)$ & $103(12.9 \%)$ & \\
$\quad$ Saccular & $85(78.0 \%)$ & $604(75.8 \%)$ & \\
$\quad$ Dissecting & $3(2.8 \%)$ & $51(6.4 \%)$ & \\
$\quad$ Other & $8(7.3 \%)$ & $39(4.9 \%)$ & \\
Aneurysm location (No., \%) & & & $<.0001$ \\
$\quad$ Internal carotid artery & $70(64.2 \%)$ & $614(77.0 \%)$ & \\
$\quad$ Middle cerebral artery & $8(7.3 \%)$ & $35(4.4 \%)$ & \\
$\quad$ Posterior cerebral artery & $0(0 \%)$ & $15(1.9 \%)$ & \\
$\quad$ Basilar artery & $16(14.7 \%)$ & $28(3.5 \%)$ & \\
$\quad$ Other & $15(13.8 \%)$ & $105(13.2 \%)$ & \\
Aneurysm ruptured at initial & $13(11.9 \%)$ & $63(7.9 \%)$ & .155 \\
$\quad$ presentation (No., \%) & & & \\
Multiple PEDs used (No., \%) & $34(31.2 \%)$ & $274(34.5 \%)$ & .499 \\
\hline
\end{tabular}

a $P$ values for aneurysm size and neck size were calculated with Wilcoxon rank sum tests. $P$ values for categoric variables were calculated with $\chi^{2}$ tests.

${ }^{\mathrm{b}}$ Of the 797 aneurysms treated with PEDs alone, size data were not available for 8 aneurysms. Of the 109 aneurysms treated with PED/coil, size data were not available for 2 aneurysms.

c Of the 797 aneurysms treated with PEDs alone, data regarding the number of PEDs used were not reported for 2 aneurysms.

aneurysms were also more likely to require multiple PEDs during treatment (Table 3). There was also a statistically significant difference in the location of aneurysms treated between the 2 groups $(P<.0001)$. There were significantly fewer internal carotid artery aneurysms treated in the PED/coil cohort compared with the PED alone group $(64.2 \%$ versus $77 \%, P=.006)$. There were significantly more basilar artery aneurysms treated by $\mathrm{PED} /$ coil compared with PED alone (14.7\% versus 3.5\%, $P<.0001)$. There was no statistically significant difference in presentation with subarachnoid hemorrhage between the 2 groups (PED/coil 11.9\% versus $\mathrm{PED}$ alone $7.9 \%, P=.155)$.

Overall, 13 of $104(12.5 \%)$ patients in the PED/coil cohort experienced a major neurologic complication and/or mortality versus 54 of $689(7.8 \%)$ patients in the PED alone cohort $(P=.13)$ (Table 4). Neither the overall nor the individual complication rates reached statistical significance.

\section{DISCUSSION}

While the use of adjunctive coil embolization with the PED is not novel, there are questions regarding the efficacy of, and the potential for, increased complications with this strategy compared with PED embolization alone. Certain authors have advocated coil embolization as a method of improving occlusion rates and minimizing the potential for catastrophic aneurysm rupture following the use of flow-diverting stents. ${ }^{23,25,26}$ Others have argued that the addition of coil embolization to the procedure yields no significant added advantage in regard to treatment efficacy. ${ }^{21}$ However, our single-center results, which have been previously presented, did identify a statistically significant increase in the need for retreatment with a strategy of PED alone versus $\mathrm{PED} /$ coil. $^{27}$ 
Table 3: Multiple PED use

\begin{tabular}{|c|c|c|c|c|c|}
\hline \multirow[b]{2}{*}{ Procedure } & \multicolumn{3}{|c|}{ Aneurysm Size (\%) $(n / N)$} & \multirow[b]{2}{*}{$P$ Value $^{\mathrm{a}}$} & \multirow[b]{2}{*}{ Total } \\
\hline & Small & Large & Giant & & \\
\hline PED alone ${ }^{b}$ & $25.8 \%(113 / 438)$ & $43.7 \%(129 / 295)$ & $53.7 \%(29 / 54)$ & $<.001$ & $34.5 \%(274 / 795)$ \\
\hline PED/coil ${ }^{c}$ & $18.2 \%(6 / 33)$ & $32.3 \%(20 / 62)$ & $66.7 \%(8 / 12)$ & .010 & $31.2 \%(34 / 109)$ \\
\hline All subjects & $25.3 \%(119 / 471)$ & $41.7 \%(149 / 357)$ & $56.1 \%(37 / 66)$ & $<.001$ & $34.1 \%(308 / 904)$ \\
\hline
\end{tabular}

${ }^{a} P$ values were calculated using Fisher exact tests.

${ }^{b}$ Of the 797 aneurysms treated with the PED alone, data regarding the number of PEDs used were not available for 2 aneurysms treated; thus, 795 is used as the total denominator. Of these 795 aneurysms, size data were not available for 8 aneurysms. All 795 are included in the total calculation, but only 787 are included in the aneurysm-size categories. ' Of the 109 aneurysms treated with PED/coil, size data were not available for 2 aneurysms. All 109 are included in the total calculation, but only 107 are included in the aneurysm-size categories.

Table 4: Patient outcomes

\begin{tabular}{lccc}
\hline \multicolumn{1}{c}{ Major Complications } & $\begin{array}{c}\text { PED/Coils (n, \%) } \\
\text { (Patients = 104; } \\
\text { Aneurysms = 109) }\end{array}$ & $\begin{array}{c}\text { PED Alone (n, \%) } \\
\text { (Patients = 689; } \\
\text { Aneurysms = 797) }\end{array}$ & $\boldsymbol{P}_{\text {V Value }}^{\text {a }}$ \\
\hline Neurologic morbidity & $11(10.6 \%)$ & $48(7.0 \%)$ & .226 \\
Spontaneous rupture & $0(0 \%)$ & $5(0.7 \%)$ & $>.99$ \\
Ipsilateral intracranial hemorrhage & $3(2.9 \%)$ & $17(2.5 \%)$ & .738 \\
Ischemic stroke & $7(6.7 \%)$ & $29(4.2 \%)$ & .307 \\
Parent artery stenosis & $0(0 \%)$ & $2(0.3 \%)$ & $>.99$ \\
Cranial neuropathy & $1(1.0 \%)$ & $1(0.1 \%)$ & .245 \\
Neurologic mortality & $7(6.7 \%)$ & $23(3.3 \%)$ & .099 \\
Neurologic morbidity and mortality & $13(12.5 \%)$ & $54(7.8 \%)$ & .128 \\
\hline
\end{tabular}

${ }^{a} P$ values were calculated using Fisher exact tests.

Additionally, we previously reported our overall (31.7\%) and permanent complication (3.2\%) rates following use of the PED. ${ }^{19}$ However, we did not examine any potential differences in complications between these 2 treatment strategies. In an earlier report on the PED, Siddiqui et $\mathrm{al}^{22}$ described a patient with a giant middle cerebral artery aneurysm treated with 2 PEDs and dense coil embolization. The patient had an acute thrombosis of the PED following the procedure, which was attributed to the dense coil mass. The authors recommended avoiding dense packing of aneurysms when coil embolization is used as an adjunctive treatment with the PED.

In a recent series published by Lin et $\mathrm{al}^{23} 75$ patients treated with the PED alone were compared with 29 patients treated with the PED and adjunctive coil embolization. There was no statistically significant difference in the complication rates between the 2 groups (10.3\% with $\mathrm{PED} /$ coil versus $8.0 \%$ with $\mathrm{PED}$ alone, $P=.7)$. Lin et al found, as we did in the IntrePED study, that aneurysms treated with a strategy of $\mathrm{PED} /$ coil were statistically larger than aneurysms treated with PED alone (16.3 versus 12.4 $\mathrm{mm}, P=.02$ ). Nossek et $\mathrm{al}^{26}$ also found similar results in 25 consecutive patients with unruptured aneurysms treated with the PED and adjunctive coiling.

Szikora et $\mathrm{al}^{21}$ described their series of 19 patients with wideneck intracranial aneurysms treated with a strategy of both PED/ coil and PED alone. Initially, they treated patients with adjunctive coil embolization, maintaining low coil-packing densities; however, they switched to a strategy of overlapping PEDs without coiling in the latter part of their series. Despite the 2 differing strategies, they had similar occlusion rates at the 6-month follow-up interval. Although their overall complication rate (1 permanent nonrestricting morbidity and 1 mortality) was within the rates published in the literature, they did not specify which treatment strategy was associated with these complications.

In the IntrePED registry, there was a statistically significant difference in the aneurysm size between the 2 cohorts we evaluated $(P<.0001)$. Aneurysms treated with adjunctive coil embolization were larger in both aneurysm size and aneurysm neck size. These differences are likely related to the individual clinician's judgment in regard to the efficacy of stand-alone PED placement for this subset of aneurysms. There may have been a stronger desire to have more immediate contrast stasis during the initial treatment of larger aneurysms due to the higher chance of spontaneous rupture with increasing aneurysm size. In this instance, 2 options for increasing stasis would be to add coil embolization or to place multiple PEDs across the aneurysm neck. Potentially, the use of multiple PEDs may also increase the rate of complications during the procedure. However, we did not identify a difference in the percentage of aneurysms treated with multiple PEDs in either cohort. Patients with larger aneurysms, however, were more likely to have multiple PEDs deployed in both groups (PED alone versus PED/coil).

Another interesting finding in our analysis is the statistically significant difference in the location of aneurysms treated by either strategy. Again, this is likely related to clinical judgment in terms of the aneurysm characteristics and their relationship to the parent vessel. Additionally, endovascular surgeons may be more reluctant to use adjunctive coil embolization when using flow diverters in the posterior cerebral artery/posterior circulation, which is currently an off-label indication in some countries.

While one may presuppose a higher intraprocedural rupture rate with a strategy of PED and adjunctive coils, this was not apparent in our findings. Even with manipulation of the aneurysm wall/dome during coil embolization, there was no statistically significant increased rate of ipsilateral intracranial hemorrhage during or following the procedure. While the anatomical differences between the aneurysms in the 2 cohorts may have certainly influenced the practitioner's judgment as to the optimal treatment strategy, there were no statistically significant differences in the primary or secondary end points for either treatment strategy. Overall, the complication rates reported for the patients in the IntrePED registry for either treatment strategy are in line with those in the published literature for use of flow-diverting stents. $^{19}$

Once the decision is made to use adjunctive coil embolization, the setup and performance of the procedure may be distinctly different from those used in deploying a PED alone. First, one must decide whether to coil the aneurysm before or after placement of the flow-diverting stent. One can choose to proceed first with primary or balloon-assisted coil embolization followed by PED deployment. While this strategy would not significantly affect the deployment of the PED from a guide catheter standpoint, it does add the time required to perform the initial embolization 
to the overall procedure. Once coils are placed within the aneurysm, the microcatheter or balloon microcatheter or both are removed, allowing unencumbered navigation of the catheters for PED deployment. This technique, however, can potentially obscure visualization of the PED during deployment.

Alternatively, one can jail a microcatheter within the aneurysm and initially place the PED followed by aneurysm coiling. This strategy, however, may affect the choice of support catheters. One must ensure that the inner diameter of the guide catheter is sufficiently large enough to support simultaneous navigation of the Marksman catheter (Covidien) and the microcatheter to be used for coil embolization. The use of a second microcatheter for coiling placed through the same guide catheter as the Marksman catheter would likely preclude the use of additional catheters (ie, distal-access catheters) to support PED deployment due to limitations in guide-catheter size. Despite the increase in procedural times and/or case complexity, there was no statistically significant increase in the overall complication rate in terms of neurologic morbidity and mortality in our analysis.

\section{Limitations}

Our study is limited by its retrospective nature, with participating sites following their standard practice for treating aneurysms with PEDs. As a result, the decision to use adjunctive coil embolization was left to the discretion of the treating physician and was not standardized across centers. Because the IntrePED study was a retrospective, observational study without preplanned subgroup analysis, no prespecified differences were expected between these 2 cohorts. Additionally, no power analysis was performed. While there are certain inherent limitations with this type of study, we believe that the conclusions may still be clinically relevant.

\section{CONCLUSIONS}

Decisions about which strategy to use when faced with a complex cerebral aneurysm are made largely at the discretion of, and with the judgment of, the practitioner. There have been few large series comparing PED alone versus PED with coiling in terms of overall efficacy in aneurysm treatment. While there was a statistically significant difference in aneurysm size and location and procedural times in the IntrePED registry between our 2 cohorts, there was no statistically significant difference in overall complications. These data suggest that either strategy represents an acceptable risk profile in the treatment of complex cerebral aneurysms and warrants further investigation.

\section{ACKNOWLEDGMENTS}

We thank Ms Suzanne LaScalza and Mei Jiang, PhD, for assistance with statistical analysis. The IntrePED observational registry was funded and supported by Covidien/Medtronic, with scientific oversight of the study by the steering committee.

Disclosures: Min S. Park—RELATED: Other: Covidien/Medtronic, Comments: Covidien provided statistical analysis support for the article (as described in our acknowledgments). No money was provided as part of the preparation, writing, submission, or any other aspects of this work. Phillipp Taussky-RELATED: Consulting Fee or Honorarium: Covidien/Medtronic (Pipeline proctor). David F. Kallmes-RELATED: Grant: ev3/Covidien/Medtronic, ${ }^{*}$ Comments: support for clinical trial; Consulting Fee or Honorarium: ev3/Covidien/Medtronic, ${ }^{*}$ Comments: Steering Committee for clinical trial; Fees for Participation in Review Activities, Such as Data Monitoring
Boards, Statistical Analysis, Endpoint Committees, and the Like: ev3/Covidien/ Medtronic,* Comments: Safety Committee; UNRELATED: Board Membership: GE Healthcare Cost-Effectiveness Board*; Consultancy: ev3/Covidien/Medtronic,* Comments: clinical trials support; Grants/Grants Pending: MicroVention, ${ }^{*}$ Codman Neuro/DePuy Synthes, ${ }^{*}$ NeuroSigma, ${ }^{*}$ SurModics, ${ }^{*}$ Sequent Medical,, ev3/Covidien/Medtronic, ${ }^{*}$ Comments: support for clinical and preclinical research; Patents (planned, pending or issued): Mayo Medical Ventures, ${ }^{*}$ Comments: augmentation patent; Royalties: University of Virginia Patent Foundation (Spine Fusion); Travel) Accommodations/Meeting Expenses Unrelated to Activities Listed: ev3/Covidien/ Medtronic, ${ }^{*}$ Comments: travel to FDA panel meeting. Elad I. Levy-UNRELATED: Board Membership: Stryker (American Spinal Injury Association Impairment Scale [AIS] Clinical Advisory Board), Next-Gen Biologics (Advisory Board); Consultancy: Pulsar Vascular (unpaid); Expert Testimony: renders medical/legal opinion as an expert witness; Payment for Lectures (including service on Speakers Bureaus): Covidien/Medtronic (honorarium for lectures), Stryker; Payment for Development of Educational Presentations: Covidien/Medtronic Abbott, Comments: honorarium for training for Covidien/Medtronic and carotid training sessions for Abbott for physicians; Stock/Stock Options: Blockade Medical, Intratech Medical, Medina Medical; Other: Covidien/Medtronic (National Principal Investigator for Solitaire with the Intention for Thrombectomy as Primary Endovascular Treatment for Acute Ischemic Stroke trials). Pascal Jabbour-UNRELATED: Consultancy: Covidien (Pipeline proctor). István Szikora-RELATED: Consulting Fee or Honorarium: Covidien/ Medtronic; Support for Travel to Meetings for the Study or Other Purposes: Covidien/Medtronic; UNRELATED: Consultancy: Covidien/Medtronic, Stryker, Codman, Sequent Medical. Edoardo Boccardi-RELATED: Consulting Fee or Honorarium: Covidien/Medtronic; UNRELATED: Consultancy: Covidien/Medtronic, Stryker, MicroVention. Ricardo A. Hanel—RELATED: Consulting Fee or Honorarium: Covidien/ Medtronic; UNRELATED: Board Membership: Medina Medical; Consultancy: Stryker, Codman, MicroVention; Stock/Stock Options: Blockade Medical. Alain BonaféUNRELATED: Consultancy: Covidien/Medtronic. Cameron G. McDougall—RELATED: Consulting Fee or Honorarium: Covidien/Medtronic; UNRELATED: Consultancy: MicroVention. *Money paid to the institution.

\section{REFERENCES}

1. Fiorella D, Woo HH, Albuquerque FC, et al. Definitive reconstruction of circumferential, fusiform intracranial aneurysms with the Pipeline embolization device. Neurosurgery 2008;62:1115-20; discussion 1120-21 CrossRef Medline

2. Lylyk P, Miranda C, Ceratto R, et al. Curative endovascular reconstruction of cerebral aneurysms with the Pipeline embolization device: the Buenos Aires experience. Neurosurgery 2009;64:632-42; discussion 642-43; quiz N6 CrossRef Medline

3. Nelson PK, Lylyk P, Szikora I, et al. The Pipeline embolization device for the intracranial treatment of aneurysms trial. AJNR Am J Neuroradiol 2011;32:34-40 CrossRef Medline

4. Chalouhi N, Zanaty M, Whiting A, et al. Safety and efficacy of the Pipeline embolization device in 100 small intracranial aneurysms. J Neurosurg 2015;122:1498-502 CrossRef Medline

5. Zanaty M, Chalouhi N, Starke RM, et al. Flow diversion versus conventional treatment for carotid cavernous aneurysms. Stroke 2014; 45:2656-61 CrossRef Medline

6. Tse MM, Yan B, Dowling RJ, et al. Current status of Pipeline embolization device in the treatment of intracranial aneurysms: a review. World Neurosurg 2013;80:829-35 CrossRef Medline

7. Saatci I, Yavuz K, Ozer C, et al. Treatment of intracranial aneurysms using the Pipeline flow-diverter embolization device: a single-center experience with long-term follow-up results. AJNR Am J Neuroradiol 2012;33:1436-46 CrossRef Medline

8. Fischer S, Vajda Z, Aguilar Perez M, et al. Pipeline embolization device (PED) for neurovascular reconstruction: initial experience in the treatment of 101 intracranial aneurysms and dissections. Neuroradiology 2012;54:369-82 CrossRef Medline

9. McAuliffe $\mathrm{W}$, Wycoco $\mathrm{V}$, Rice $\mathrm{H}$, et al. Immediate and midterm results following treatment of unruptured intracranial aneurysms with the Pipeline embolization device. AJNR Am J Neuroradiol 2012; 33:164-70 CrossRef Medline

10. Chitale R, Gonzalez LF, Randazzo C, et al. Single center experience with Pipeline stent: feasibility, technique, and complications. Neurosurgery 2012;71:679-91; discussion 691 CrossRef Medline

11. Becske T, Kallmes DF, Saatci I, et al. Pipeline for uncoilable or failed 
aneurysms: results from a multicenter clinical trial. Radiology 2013; 267:858-68 CrossRef Medline

12. Deutschmann HA, Wehrschuetz M, Augustin M, et al. Long-term follow-up after treatment of intracranial aneurysms with the Pipeline embolization device: results from a single center. AJNR Am J Neuroradiol 2012;33:481-86 CrossRef Medline

13. Briganti F, Delehaye L, Leone G, et al. Flow diverter device for the treatment of small middle cerebral artery aneurysms. J Neurointerv Surg 2015 Jan 20. [Epub ahead of print] CrossRef Medline

14. Zanaty M, Chalouhi N, Barros G, et al. Flow-diversion for ophthalmic segment aneurysms. Neurosurgery 2015;76:286-89; discussion 289-90 CrossRef Medline

15. Navarro R, Brown BL, Beier A, et al. Flow diversion for complex intracranial aneurysms in young children. J Neurosurg Pediatr 2015; 15:276-81 CrossRef Medline

16. Chalouhi N, Zanaty M, Whiting A, et al. Treatment of ruptured intracranial aneurysms with the Pipeline embolization device. $\mathrm{Neu}$ rosurgery 2015;76:165-72; discussion 172 CrossRef Medline

17. Kallmes DF, Hanel R, Lopes D, et al. International retrospective study of the Pipeline embolization device: a multicenter aneurysm treatment study. AJNR Am J Neuroradiol 2015;36:108-15 CrossRef Medline

18. Chalouhi N, Tjoumakaris S, Phillips JL, et al. A single Pipeline embolization device is sufficient for treatment of intracranial aneurysms. AJNR Am J Neuroradiol 2014;35:1562-66 CrossRef Medline

19. Park MS, Albuquerque FC, Nanaszko M, et al. Critical assessment of complications associated with use of the Pipeline embolization device. J Neurointerv Surg 2015;7:652-69 CrossRef Medline

20. Siddiqui AH, Abla AA, Kan P, et al. Panacea or problem: flow diverters in the treatment of symptomatic large or giant fusiform vertebrobasilar aneurysms. J Neurosurg 2012;116:1258-66 CrossRef Medline

21. Szikora I, Berentei Z, Kulcsar Z, et al. Treatment of intracranial aneurysms by functional reconstruction of the parent artery: the Budapest experience with the Pipeline embolization device. AJNR Am J Neuroradiol 2010;31:1139-47 CrossRef Medline

22. Siddiqui AH, Kan P, Abla AA, et al. Complications after treatment with Pipeline embolization for giant distal intracranial aneurysms with or without coil embolization. Neurosurgery 2012;71:E509-13; discussion E513 CrossRef Medline

23. Lin N, Brouillard AM, Krishna C, et al. Use of coils in conjunction with the Pipeline embolization device for treatment of intracranial aneurysms. Neurosurgery 2015;76:142-49 CrossRef Medline

24. Dornbos D 3rd, Pillai P, Sauvageau E. Flow diverter assisted coil embolization of a very small ruptured ophthalmic artery aneurysm. J Neurointerv Surg 2013 Dec 11. [Epub ahead of print] CrossRef Medline

25. Turowski B, Macht S, Kulcsár Z, et al. Early fatal hemorrhage after endovascular cerebral aneurysm treatment with a flow diverter (SILK-Stent): do we need to rethink our concepts? Neuroradiology 2011;53:37-41 CrossRef Medline

26. Nossek E, Chalif DJ, Chakraborty S, et al. Concurrent use of the Pipeline embolization device and coils for intracranial aneurysms: technique, safety, and efficacy. J Neurosurg 2015;122:904-11 CrossRef Medline

27. Park MS, Nanaszko M, Sanborn MR, et al. Re-treatment rates after treatment with the Pipeline embolization device alone versus Pipeline and coil embolization of cerebral aneurysms: a single-center experience. J Neurosurg 2015 Dec 18. [Epub ahead of print] CrossRef Medline 